\title{
The Obesity Learning Centre (OLC) - a website supporting those working towards a healthy weight and reducing obesity levels
}

\author{
Helena Korjonen ${ }^{1}$ \\ ${ }^{1}$ National Heart Forum, London, UK
}

\begin{abstract}
Objectives: Develop a website, the OLC, which supports those people who work on promoting a healthy weight and tackling obesity. Research shows that original networks where sharing of information and peer interaction take place create solutions to current public health challenges.
\end{abstract}

Methods: Considerations that are relevant when building a new information service as well as the technical set up and information needs of users were taken into account prior to building the OLC and during continuous development and maintenance.

Results: The OLC provides global news, resources and tools and link out to other networks, websites and organisations providing similar useful information. The OLC also uses social networking tools to highlight new and important information.

Discussion: Networks contribute to a stronger community that can respond to emerging challenges in public health. The OLC improves connections of people and services from different backgrounds and organisations. Some challenges exist in the technical set up and also because of other aspects, e.g. public health information and differing information needs.

Conclusion: Public health work programmes should include networking opportunities where public policy can be disseminated. The provision of necessary tools and resources can lead to better decision-making, save time and money and lead to improved public health outcomes.

Key Words: public health, obesity, information services, website

\section{Introduction}

In the last 25 years, overweight or obesity in England has tripled with a forecast $24 \%$ of boys being classed as obese in 2025 (1). Obesity increases the risk of chronic life limiting conditions including diabetes, cardiovascular disease and cancer. Obesity is not caused by one contributing factor but is a very complex area to understand and address. We live in an obesogenic environment where we are surrounded by factors that affect our health and 
weight. Obesity has been described as a 'health time bomb'(1) costing the healthcare services in England millions of pounds and other indirect costs are thought to be around $£ 3.6$ billion (1). No single solution exists to solve the obesity problem but there is a need to build up evidence of what interventions work and involve multiple disciplines to address obesity in local areas.

Research shows that networking activity, such as exchanging ideas, practices and experiences with peers improve practice and quality of working life (2) and that locally conducted and published initiatives play an important role in changing the professional practice of health care providers (3). Sharing information can create a sense of collaboration and trust amongst individuals and beneficial partnerships can form that promote the exchange of ideas, practices and tools (4). Research shows that investment in networks may provide a cost-effective solution to disseminate information, policies and programmes (3). By sharing local initiatives and information it will reduce the reinvention of initiatives and therefore reduce cost and effort at the point of set-up.

Public health programmes should include a plan for creating opportunities for network interaction in order to improve adoption and diffusion of public policy and to avoid delays and diminished public health investment (3). One successful model where new ideas and practices rapidly spread through interpersonal communication was the implementation of the Framework Convention for Tobacco Control (FCTC tobacco) through the GLOBALink ${ }^{1}$ network, which first began as an email discussion list and then became a website. Many websites have since been built based on this proven network model and they effectively bridge the gap between research, policy and practice, they are able to translate research into action.

\section{Obesity Learning Centre}

The National Heart Forum (NHF) ${ }^{2}$, a charitable alliance committed towards co-ordinating public health policy development towards reducing the risk of coronary heart disease and related conditions, received funding from the Department of Health and Department for Education in England to develop a website that supports those people who work on promoting a healthy weight and tackling obesity, the obesity delivery chain. This website became the Obesity Learning Centre (OLC) ${ }^{3}$. We aimed to build on the success of original networks such as GLOBALink and findings of research where sharing information and peer interaction are known to create solutions to current public health challenges. The OLC website is also a key component of the development of chronic disease prevention information services at the NHF.

The OLC sets out to strengthen and support the obesity delivery chain, e.g. local capacity and capabilities, to prevent and treat overweight in children and adults. The website is aimed at practitioners from a variety of backgrounds, those working in schools and nurseries, academics and researchers, health care professionals, local government employees who may

\footnotetext{
${ }^{1}$ www.globalink.org/ (Accessed 21 October 2010)

${ }^{2}$ www.heartforum.org.uk (Accessed 27 January 2011)

${ }^{3}$ www.obesitylearningcentre-nhf.org.uk (Accessed 27 January 2011)
} 
work on a wide range of activities such as planning green space and urban environments, developing opportunities for physical activity, planning school menus or are conducting research in obesity. Initial discussions with relevant stakeholders (Table 1) took place starting in the autumn of 2008 and throughout 2008 until the site went live. The discussions consisted of presentations and open questions and answers sessions as well as telephone interviews with specific individuals. The discussions revealed that these individuals want to share local and national initiatives with one another and have the opportunity to discuss their work with peers in an online environment. It was also clear that the website should be independent from any influences and have no commercial links. Although the site has a key role in supporting professionals in England in line with a national obesity strategy, it is also aimed at an international audience hoping that it may lead to collaboration and learning between the different users.

Table 1: Stakeholders that were consulted during project set up

\begin{tabular}{|l|}
\hline Health professionals (e.g. doctors and nurses) \\
\hline Local government/authorities \\
\hline Relevant committees/groups (e.g. Healthy Towns) \\
\hline Primary Care Trusts (PCTs), public health observatories \\
\hline Government and government agencies \\
\hline Voluntary and community sector (charities, NGOs, etc.) \\
\hline Dietitians/nutritionists \\
\hline Policy civil servants \\
\hline Professional bodies for health (e.g. Royal Colleges, UKPHA etc.) \\
\hline Schools \\
\hline Physical activity and sports professionals \\
\hline Academia \\
\hline International, intergovernmental organisations and NGOs \\
\hline Information providers/libraries (e.g. public health and NHS libraries) \\
\hline
\end{tabular}

\section{Methods}

\section{Considerations on the role of the OLC}

There were a number of considerations that needed to be kept in mind during the set up of the OLC.

We have already mentioned the need for the site to remain free from commercial and other influence (e.g. Government, political, economic). The reason behind this is that individuals expressed a concern for them being influenced by advertising seen on the site, or the potential influence on content or on their opinions expressed in the discussion forum.

It was also important that the OLC did not aim to replace any existing information service or website. Other services exist that provide content that is relevant, e.g. obesity data, local or regional information aimed at the public or educational websites. It was clear that the OLC was a website aimed at guiding professionals to the right information as well as highlighting 
new information but then directing users to the right location for further information. The OLC works particularly closely with the obesity regions around England, some of who have their own websites, the National Obesity Observatory (NOO) who analyse obesity data and intelligence and Change4Life, a national social marketing campaign aimed to improve the eating and physical activity habits of the public.

It was also clear that the OLC needed to build on existing information services provided by the NHF and compliment our work. The OLC concentrates on providing content on obesity, but the other information services are extended to other avoidable chronic disease topics including obesity.

We recognise the success of the likes of GLOBALink and wanted to make improvements to the model, move it in line with new developments in web 2.0 and 3.0 making the site more interactive and user driven. For us, the success of the website is when the users drive the development of the content and functionality and the site almost becomes a user managed entity with vibrant content. Of course we need to provide some information, e.g. news and the latest resources we harvest, but we want the site to be interactive and for the users to contribute to the content.

The OLC must be able to bring networks and groups together, allowing them to share discussion and material within a closed network. Many expert groups exist that physically meet on a regular basis, but information and knowledge is not gathered, classified and stored together in an accessible manner. Closed network pages on the OLC allow them to manage their own content with editorial rights to do so. Examples of closed networks are the regional obesity leads and healthy towns network members across England.

A key requirement is that the OLC must enable the users by providing information and resources relevant to obesity. It needs to allow the user to search and find that information. It must also allow the user to select how s/he accesses the information, by browsing the website, by signing up for newsletters or RSS feeds.

A topic which was discussed at length during the set up of the website was the need for users to register and login to access content. The original plan was to ensure that the user was protected through a login mechanism and that a stringent registration process was in place which included checking the validity of information provided by a new user through a referee process. A heavy administration burden as well as being tedious for users registering and waiting to be registered, it was fortunate that a change in government requirements for websites of this nature came about which allowed us to relax the registration process.

\section{Technical set up and selection of software}

At the beginning of the project, presentations were given to groups of people followed by informal discussions and interviews with a selection of stakeholders to get their impressions of what functionality the website might have and what it might look like. This formed the initial build specification used to source appropriate software to build the website. The initial technical team consisted of two IT consultants who sourced and managed the website contractual phase of the project set up. It was agreed that a content management system (CMS) was necessary to build the site to allow for non-technical staff to edit the site in the future. The website was built during August and September 2009 and the site went live on 2 
November 2009 as agreed with the funders. Very early on in the project it was realised that the CMS system selected for the project was not as flexible with its functionality as was anticipated. It was clear that the software required significant technical development and updating the site proved complex. This caused additional stress on the project as a new CMS had to be sourced as well as the continuation to build with the existing CMS in order to go live at the agreed date.

In early 2010, we sourced a suitable CMS that we were confident could grow with the project and the NHF as an organisation. The selected CMS Easysite by EIBS is an off the shelf CMS with modules that can be selected and bolted on when required in the project. The OLC was rebuilt and content migrated during March and April 2010 going live in May 2010.

The selection of the CMS for technical platform was an important decision. It was anticipated that we needed a CMS that would also be used for our other information services, including the NHF website. The CMS needed to be compatible with our existing systems and new systems to come during the development of our information services.

\section{Information needs and benchmarking- evaluation methods}

It is important to conduct regular information needs analyses for all information services to ensure we are addressing information needs of those working in public health. Research has shown the information needs of public health practitioners are not met at all (5) and there needs to be a strategy in place to ensure needs are met. Assessing information needs of public health practitioners is difficult as they often do not know what they are missing (6). Research shows that as information providers we need to raise awareness, increase access and decrease barriers of use, improve information seeking behaviour (6;7). Revere et al. (8) identified a number of improvements that can be made to meet the information needs of public health practitioners in order to design an interactive knowledge management system and those findings are a useful basis on which to build an evaluation strategy.

We drafted an evaluation policy of how we meet information needs and the methods used are a combination of:

- analysing statistics of what users do on the site

- run user needs surveys using online questionnaires twice a year

- use a built in poll mechanism to ask specific questions of users

- ask users to rate on and comment on pages

- regular contact with our users through email, telephone or face-to-face meetings.

We also use various benchmarks which are appropriate for information projects (this list is not exhaustive):

- Comparisons to be made with competitors, collaborators and the information community

- Compliance with Copyright Act and the Data Protection Act.

- Best practice in dissemination of information

- Monitor information standards

- Conduct research into information provision and new technology to continuously develop the technological capabilities 
- Using Google Analytics and reporting tools for traffic, referrals, access, users and content data

- Quality testing standard developed in-house

- Accessibility - benchmark against available standards on accessibility

- Cost-effectiveness

We also meet regularly with our funders to discuss information needs, benchmarking and development requirements. Regular reports are submitted and published on the website for transparency. Establishing information needs, whether the OLC meets those needs, and benchmarking all contribute to our evaluation plan of the project and ultimately if it can be considered a 'success'.

\section{Results:}

The OLC (Figure 1) went live first on 2 November 2009 and with a new CMS in May 2010. The site has had around 1,100 visitors each month with visitors from around 40 countries. On average the site sees around 700 new visitors ${ }^{4}$ (approximately $60 \%$ of all users) each month.

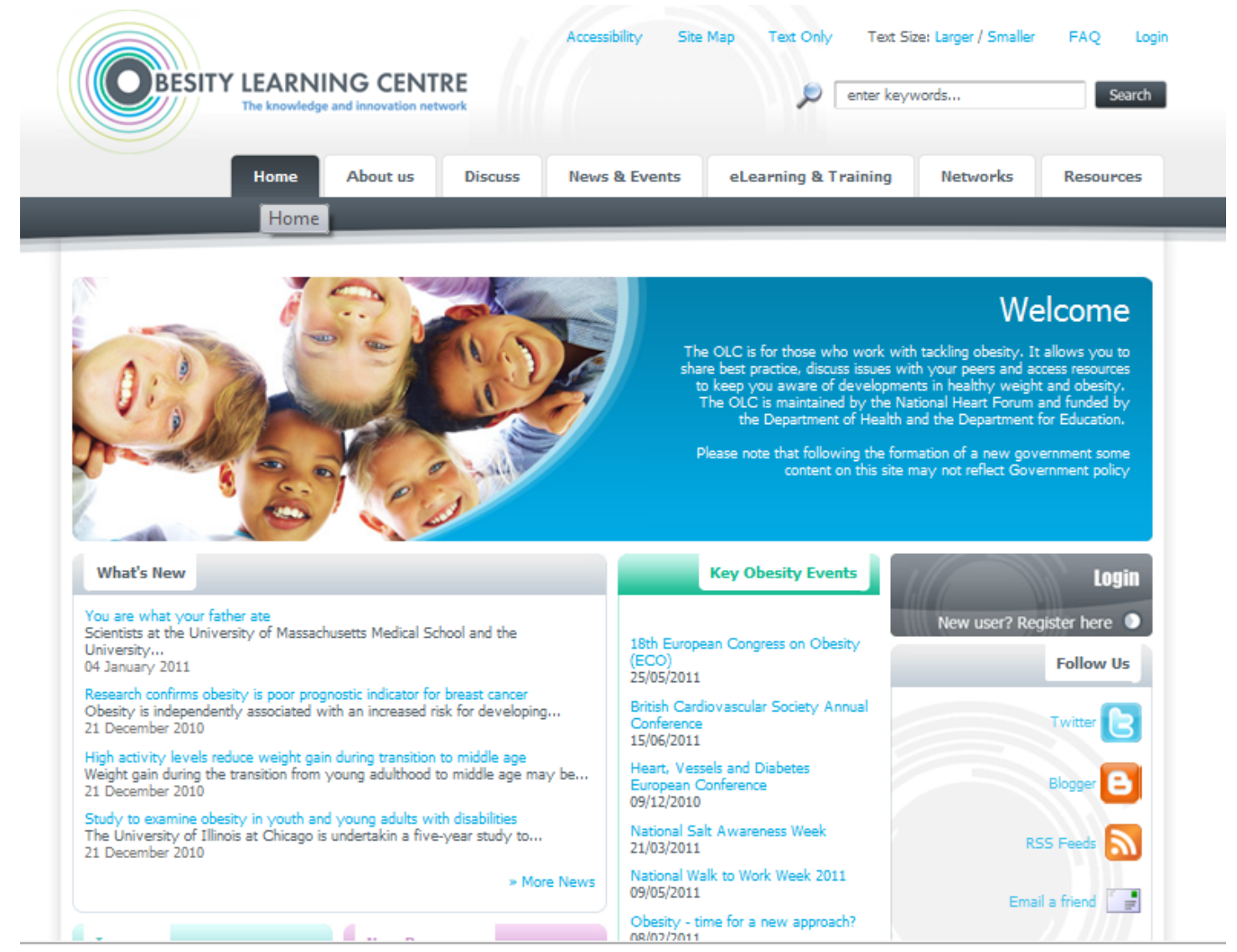

Figure 1: Obesity Learning Centre - homepage

\footnotetext{
${ }^{4}$ Unique IP addresses
} 
The most popular pages on the OLC are the resources directory, elearning, case studies, obesity general news, network (open and closed) pages and events calendar. It is impossible to within this paper describe all pages and content available on the OLC but we will highlight certain aspects of the site that we think will be of particular interest.

In order to make it easier for the user to find content, we categorise all the content according to job role of those who may be interested in that particular item, according to resource type (report, guideline, media etc.) and by topic (commissioning, planning, education, environment etc.). This (a) allows us to use internal feeds and directories that pull the information from the categories onto pages (b) allows the users to search for information (c) allows the user to browse for information according to their job role and (d) allows the user to sign up for relevant automated feeds that arrive in their inbox, on their mobile or their RSS reader. Figure 2 shows our resources directory which demonstrates these features as well as provide free text search fields.

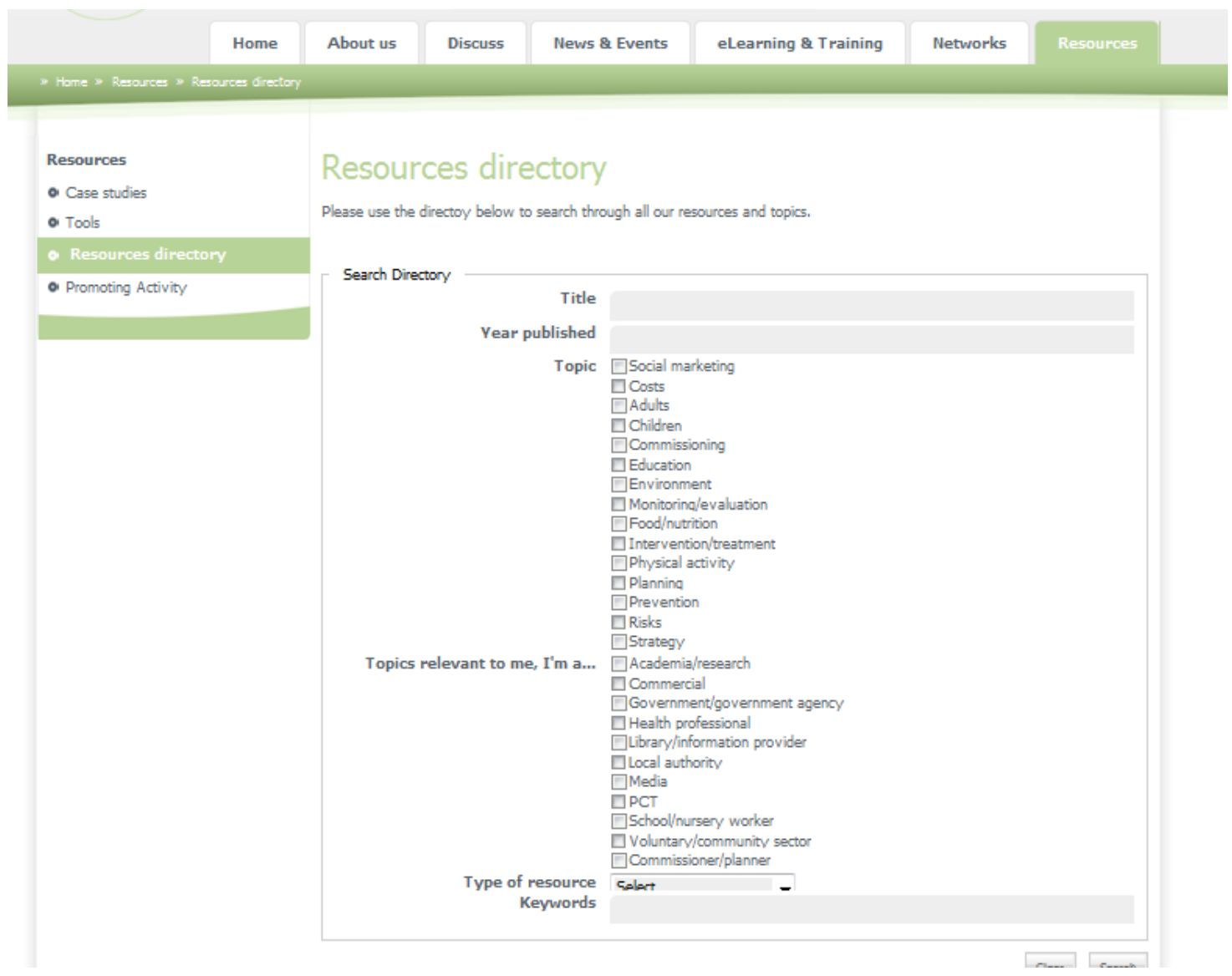

Figure 2: Category driven content: according to role, resource type and topic

The case studies (Figure 3) are local, regional and national initiatives of what has been tried and tested in regions. Case studies can be submitted to us by uploading them to the directory where we categorise them. Like with all other content, case studies can be found by selecting a topic, searching using free text search fields or by browsing all case studies. 
The Obesity Learning Centre (OLC) - a website supporting those working towards a healthy weight and reducing obesity levels

\begin{tabular}{|c|c|c|c|}
\hline Title & $\begin{array}{l}\text { Year } \\
\text { published }\end{array}$ & Summary & $\begin{array}{l}\text { Type of } \\
\text { resource }\end{array}$ \\
\hline Walk to school initiatives:Norwood... & 2010 & $\begin{array}{l}\text { Walk Once a Week (WoW) is a } \\
\text { simple... }\end{array}$ & Case study \\
\hline $\begin{array}{l}\text { Walk Once a Week Ray Lodge } \\
\text { Primary... }\end{array}$ & 2010 & $\begin{array}{l}\text { Walk Once a Week (WoW) is a } \\
\text { simple... }\end{array}$ & Case study \\
\hline Sticky Fingers & 2010 & $\begin{array}{l}\text { Sticky Fingers, part of } \\
\text { Southampton's... }\end{array}$ & Case study \\
\hline Snack Right ChaMPs Public Health... & 2010 & $\begin{array}{l}\text { Snack Right is targeted at parents } \\
\text { and... }\end{array}$ & Case study \\
\hline School Food Trust database of case... & & This collection of case studies is... & Case study \\
\hline School and Community Cycling... & 2010 & The school has embraced pupils'... & Case study \\
\hline Saturation Point & 2010 & $\begin{array}{l}\text { Barking and Dagenham Council } \\
\text { have... }\end{array}$ & Case study \\
\hline $\begin{array}{l}\text { Promoting Active Travel to NHS } \\
\text { Bristol... }\end{array}$ & 2010 & $\begin{array}{l}\text { The scheme was triggered by the } \\
\text { need... }\end{array}$ & Case study \\
\hline $\begin{array}{l}\text { Preventing obesity at weaning: } \\
\text { parental... }\end{array}$ & 2010 & This is a link to a pre-publication... & Case study \\
\hline Nippers Nutrition & 2010 & $\begin{array}{l}\text { Trading Standards East Midlands and } \\
\text { the... }\end{array}$ & Case study \\
\hline $\begin{array}{l}\text { National Child Measurement } \\
\text { Programme }\end{array}$ & 2010 & $\begin{array}{l}\text { NHS Bedfordshire's aim was to use } \\
\text { the... }\end{array}$ & Case study \\
\hline Make it count & 2010 & $\begin{array}{l}\text { Make It Count is a } 12 \text {-week } \\
\text { programme... }\end{array}$ & Case study \\
\hline $\begin{array}{l}\text { Lighten Up : Weight management } \\
\text { services... }\end{array}$ & 2010 & $\begin{array}{l}\text { The Lighten Up model was put in } \\
\text { place... }\end{array}$ & Case study \\
\hline Healthy eating in schools & 2007 & Case studies of healthy eating in... & Case study \\
\hline HealthKick: a nutrition and physical... & 2010 & This paper describes HealthKick, a... & Case study \\
\hline Food Vision case studies & 2010 & This section features case studies,... & Case study \\
\hline Eatrightliverpool (phase 1) & 2010 & $\begin{array}{l}\text { Liverpool and Merseyside has 30\% } \\
\text { more... }\end{array}$ & Case study \\
\hline BUFFALO & 2010 & $\begin{array}{l}\text { BUFFALO (Burnley food and fitness } \\
\text { aimed... }\end{array}$ & Case study \\
\hline Brownhills cluster healthy living... & 2010 & $\begin{array}{l}\text { The long-term purpose of the project } \\
\text { is... }\end{array}$ & Case study \\
\hline Adventure playgrounds & 2010 & The children's charity London Play... & Case study \\
\hline
\end{tabular}

Figure 3: Case studies on the OLC

The OLC provides current global news in obesity and all news items are archived in a news directory (Figure 4). The news is displayed on the homepage (Figure 1) and users can sign up for RSS feeds to receive news as they are added. We also use Twitter to highlight new and important news items and resources that have gone up on the OLC. When selecting news items for the news directory on the website we follow an internal appraisal and selection policy. We do not report on news that is promotional in nature (e.g. for commercial gain) or is judged to have a potential commercial bias. We also do not report opinion pieces. The OLC blog (9) is used for discussing issues related to obesity and opinions of obesity experts that contribute to the blog, again where they are free of commercial ties or promotional intention. 


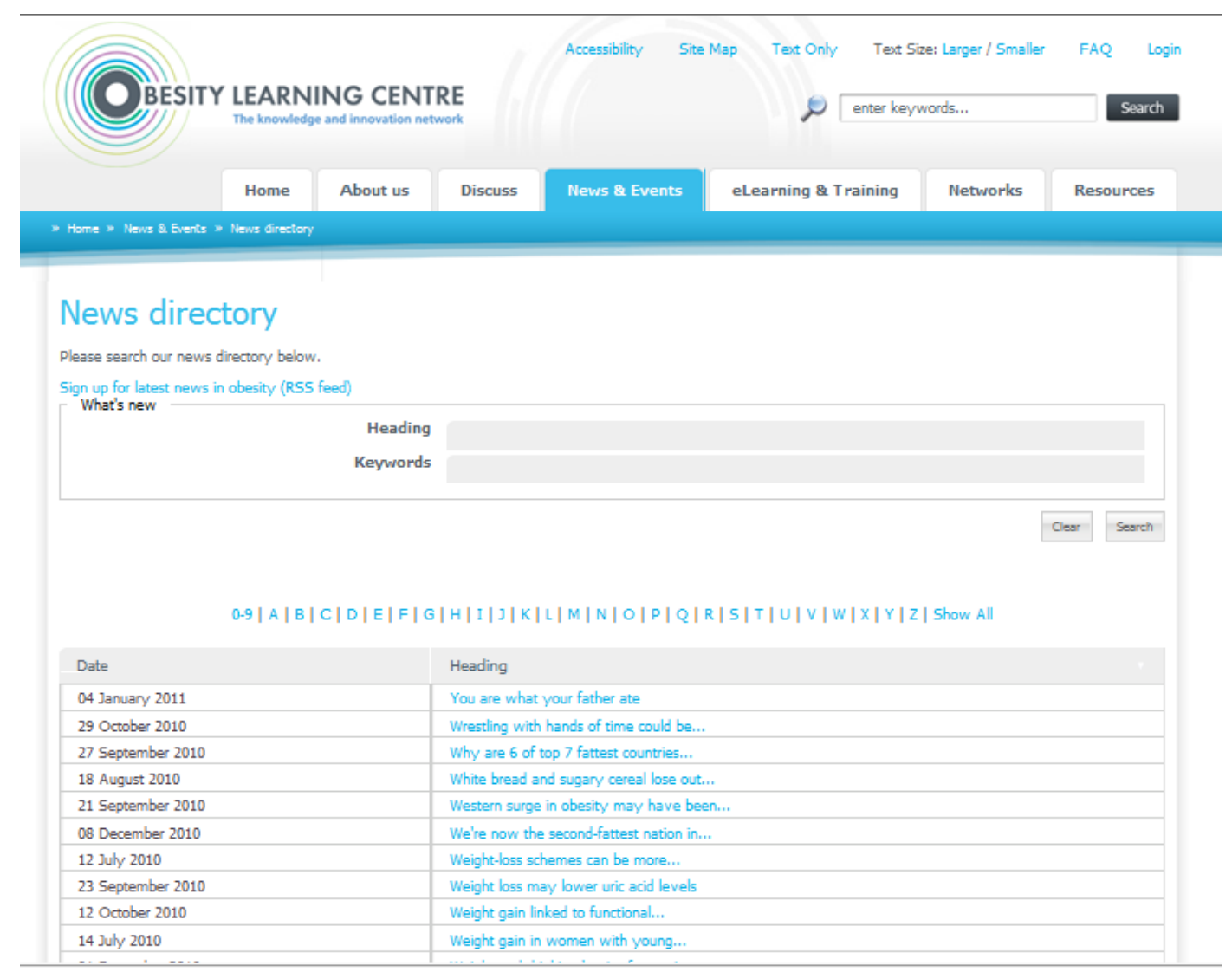

Figure 4: News directory

\section{Discussion}

Many websites provide information around obesity, but it is difficult for the user to find that information with the limited time that they have in keeping up-to-date. Improving access to useful information is much more challenging in publish health than in biomedicine as public health professionals need to cover a broad range of subjects and sources (7) and do not always know what they are missing $(6 ; 7)$. It has also been stated that the public health workforce do not just need data or citations, they need filtered and synthesised information with training and support on how to use it in the form of information literacy training (6).

The OLC is a customised toolkit which sources and publishes documents, news, policy updates and provides information in various push and pull formats by allowing the user to search for and download information, sign up for feeds or email alerts and providing other customised ways of finding information by their job role or by topic category.

The OLC also harvests and publishes case studies, tools and local, national and international initiatives of work that have been tried and evaluated. By improving connections of people and services through networks; innovation and local, regional and national initiatives can be shared with ease and therefore improve quality of services. Sharing existing practice enables health initiatives to progress more quickly with lower set up costs.

Networks can also support professional development via peer support contributing towards a stronger community that can respond to emerging challenges. The OLC supports a 
discussion forum and closed network pages where discussion about obesity issues is encouraged, although it has to be said that the discussion forum is proving to be a challenging development and few discussions are taking place.

There were challenges during the build of the OLC, some which cannot be anticipated at the start of a project. During the build of the OLC the branding and designing visuals of the site was a lengthier process than anticipated. In general involving one or several partners mean that more people need involvement in all aspects of the set up and approval processes of the website.

It was also important to build relationships with existing information providers in obesity and address any concerns that arise as early as possible. Initial difficulties can be around potential overlaps of websites or existing services with that of a new service and even a resistance to the set up of such a service if it is seen as competitive or having an impact on another organisation's objectives. We had several meetings with organisations to reassure that we were not replacing any service or intending to occupy their space and regular communication between organisations continues.

Another challenge is that the OLC aims to reach different kinds of users all with differing levels of information literacy skills but also a workforce with differences in responsibilities and information needs. The majority users of the site are from the health sector, academia and government agencies but we also have users from the local government, schools, nongovernment organisation and community organisations. The mixture of users will require different types of information from a variety of sources. We also know that around $80 \%$ of our users are from the UK which means that $20 \%$ are international users with different needs. It is difficult to ensure that all users feel that the OLC is providing what they need and we continuously review our development plan and run user needs surveys to ensure that we meet the needs of the community. In our last survey, $97 \%$ of our users told us that they find exactly what they need or at least related information to what they need on the site (10). However, a question is, do we reach everyone in the audience that ought to access the OLC? It is still uncertain how many professionals interested in public health issues are unable to access the Internet, or do not have time to access it, and therefore miss important content to their work. Much public health information is grey literature disseminated electronically and very little such information is likely to be using the traditional print methods, due to the time it takes to send it out and also cost implications. Also, the amount of grey literature public health information that is generated by various public and independent bodies today is so large that it would not be logical to disseminate this information in print. It would be useful future research to examine the quantity and format of public health information generated and also examine the information needs of public health professionals, including access issues.

Government election time is a challenge when funding is provided from government sources. During spring of 2010 the election announcement was made. The pre-election period in the United Kingdom (UK) is described as Purdah, the time between an announced election and the final election result, during which time government parties discuss policy development with civil servants and certain aspects of work, such as consultations, are put on hold. Any work that is funded by existing government departments need to be put on hold as any decisions with regards to policy are postponed until after the election period. The OLC was not updated during the purdah period and afterwards subject to review with the existing obesity strategy by the new government. 
The new forming government may take some time in reviewing existing policies and the purdah period is a challenge when managing an information service. It may also be that there are changes in strategy and restructuring of workforce, which changes our audience or the objectives of the OLC to align with new policy. However, as we have an international audience, we need to ensure that the OLC is not alienating those users. Therefore the development plan of the OLC is constantly reviewed and critiqued to ensure that it meets the needs of our users. Our recent survey (10) shows that users want to see more obesity news, peer-reviewed research, tools and case studies with respondents saying that the site provides relevant and up-to-date information and covers the topics they find useful. The survey also showed that we need to do some work in communicating with our users and promoting the site.

\section{Conclusion}

The OLC was developed by the NHF and has proved to be an efficient resource for users to get obesity information but also to share information with other like-minded colleagues or across affiliations. Obesity professionals can access and share local, regional, national and international information and find or receive information in a variety of ways and sort the information according to type, topic or their job role. This makes information more userfriendly. Our information needs surveys reveal that the users consider the website a valuable and needed function for their work in tackling obesity.

Future development work is dictated by where the needs are for the obesity workforce. These needs vary as and when strategy and policy are reviewed and when new evidence comes to light. This means that development plans need to be revisited on a regular basis and we need to frequently run user needs surveys to ensure we meet the current information needs.

We believe that any public health programme should include networking opportunities for the workforce where public policy can be disseminated with the goal that uptake of evidencebased policy is improved. Informal networks and communities can provide the necessary tools, partnerships and resources that could lead to improved public health outcomes.

\section{Glossary}

Case studies = a study that attempts to determine what factors led to success or failure, e.g. obesity initiatives implemented and evaluated in local or regional areas.

Content management system (CMS) = designed to simplify the publication of web content to web sites and mobile devices - in particular, allowing content creators to submit content without requiring technical knowledge of HTML.

Grey literature $=$ information produced in electronic and print formats not controlled by commercial publishing, e.g. reports, presentations, white papers etc.

Green space $=$ land covered with vegetation, e.g. parks, fields and other open land within built-up area.

Information literacy $=$ the ability to locate, understand, evaluate, utilize, and convey information 
Obesogenic environment $=$ set of circumstances that encourages people to eat and drink more calories than they expend and to become obese.

Purdah $=$ in the UK, the time between an announced election and the final election result, during which time government departments develop guidance and policy.

RSS feeds = is a family of web feed formats used to publish frequently updated works, e.g. blog entries, news headlines, audio, and video, in a standardized format.

Urban environment $=$ cities, towns with higher population density compared to areas surrounding

Tools $=$ encompass entities that facilitate effective action, e.g. programmes, resources or applications that can be used when implementing initiatives.

\section{Conflicts of Interest:}

No conflict of interest has been declared.

\section{Correspondence}

Helena Korjonen, Associate Director Information Services, National Heart Forum, Victoria House, 7th Floor, Southampton Row, London,WC1B 4AD, England.

Email: helena.korjonen@heartforum.org.uk

\section{References}

[1] UK Government Foresight Programme. Tackling Obesities: Future Choices (the Foresight report). 2007 Oct 17.

[2] Guindon GE, Lavis JN, Becerra-Posada F, Malek-Afzali H, Shi G, et al. 2010. Bridging the gaps between research, policy and practice in low- and middle-income countries: a survey of health care providers. CMAJ. 182(9), E362-72. http://dx.doi.org/10.1503/cmaj.081165

[3] Wipfli HL, Fujimoto K, Valente TW. 2010. Global tobacco control diffusion: the case of the framework convention on tobacco control. Am J Public Health. 100(7), 1260. http:// dx.doi.org/10.2105/AJPH.2009.167833

[4] Loschen W, Seagraves R, Holtry R, Hung L, Lombardo J, et al. INFOSHARE - An information sharing tool for public health during the 2009 Presidential Inauguration and H1N1 outbreak 2010 [cited 2011 Jan 6]; 2 Available from http://firstmonday.org/htbin/cgiwrap/bin/ ojs/index.php/ojphi/article/viewFile/3031/2751

[5] LaPelle NR, Luckmann R, Hatheway Simpson E, Martin E. 2006. Identifying strategies to improve access to credible and relevant information for public health professionals: a qualitative study. BMC Public Health. 6(89).

[6] Rambo N. 2001. Public Health Outreach Forum: lessons learned. Bull Med Libr Assoc. 89(4), 403-06.

[7] Lasker RD. 1998. Challenges to accessing useful information in health policy and public health: and introduction to a national forum held at the New York Academy of Medicine. J Urban Health. 75(4), 779-84. http://dx.doi.org/10.1007/BF02344507 
The Obesity Learning Centre (OLC) - a website supporting those working towards a healthy weight and reducing obesity levels

[8] Revere D, Turner AM, Madhavan A, Rambo N, Bugni PF, et al. 2007. Understanding the information needs of public health practitioners: a literature review to inform design of an interactive digital knowledge management system. J Biomed Inform. 40, 410-21. http:// dx.doi.org/10.1016/j.jbi.2006.12.008

[9] Obesity Learning Centre. OLC Blog 2011 Jan 21 Available from http:// obesitylearningcentre.blogspot.com/

[10] Obesity Learning Centre. Obesity Learning Centre - user needs study. National Heart Forum; 2011 Jan 20. 